Introduction/Background* Cervical cancer ranks fourteenth among all types of cancer. Several factors of socioeconomic status, including education level, and individual or environmental economic status, have been associated with the risk of advanced cancer at diagnosis.

Methodology This cross-sectional study was conducted on 108 female diagnosed with cervical cancer at the Obstetrics and Gynecology Department of Prof. Dr. RD Kandou Man-

Abstract 284 Table 1 Distribution of demographic characteristics of studied women

\begin{tabular}{|c|c|c|c|}
\hline Characteristics & Total & Early stage & Late stage \\
\hline \multicolumn{4}{|l|}{ Age at diagnosis } \\
\hline $25-39$ & 44 & 28 & 16 \\
\hline $40-59$ & 61 & 36 & 25 \\
\hline$>60$ & 3 & 1 & 2 \\
\hline Mean \pm SD & $36 \pm 24.3$ & $21.6 \pm 14.9$ & $14.3 \pm 9.4$ \\
\hline \multicolumn{4}{|l|}{ Pap Smear screening } \\
\hline Ever & 27 & 21 & 6 \\
\hline Never & 81 & 45 & 37 \\
\hline \multicolumn{4}{|l|}{ Active sexual intercourse } \\
\hline Yes & 64 & 45 & 19 \\
\hline Not & 44 & 20 & 24 \\
\hline \multicolumn{4}{|l|}{ Sexual partner } \\
\hline$>1$ & 19 & 3 & 16 \\
\hline 1 & 89 & 62 & 27 \\
\hline \multicolumn{4}{|l|}{ Age at first sexual intercourse } \\
\hline$\leq 20$ years & 11 & 4 & 7 \\
\hline$>20$ years & 97 & 61 & 36 \\
\hline \multicolumn{4}{|l|}{ Education level } \\
\hline No school & 5 & 1 & 4 \\
\hline Primary & 7 & 3 & 4 \\
\hline Junior High School & 19 & 8 & 11 \\
\hline Senior High school & 23 & 11 & 12 \\
\hline Diploma & 15 & 9 & 6 \\
\hline College & 39 & 33 & 6 \\
\hline Mean \pm SD & $18 \pm 11.3$ & $10.6 \pm 10.4$ & $7.2 \pm 3.2$ \\
\hline \multicolumn{4}{|l|}{ Job } \\
\hline Civil servants & 35 & 24 & 11 \\
\hline Private & 23 & 15 & 8 \\
\hline Traders & 16 & 9 & 7 \\
\hline Farmer & 8 & 3 & 5 \\
\hline Housewife/not working & 26 & 14 & 12 \\
\hline Mean \pm SD & $21.6 \pm 9.1$ & $13 \pm 6.9$ & $8.6 \pm 2.6$ \\
\hline \multicolumn{4}{|l|}{ Income } \\
\hline$<$ Rp. $1,500,000$ & 31 & 13 & 18 \\
\hline Rp. $1,500,000$ - Rp. $2,500,000$ & 14 & 5 & 9 \\
\hline Rp. $2,500,000-3,500,000$ & 35 & 22 & 13 \\
\hline$>$ Rp. $3,500,000$ & 28 & 25 & 3 \\
\hline Mean \pm SD & $27 \pm 7.9$ & $16.3 \pm 7.8$ & $10.75 \pm 5.5$ \\
\hline
\end{tabular}

ado. A researcher-made questionnaire was used to collect data about social economic status. The outcomes were analyzed using linear regression methods. Data were analyzed using SPSS 23.

Result(s)* The mean age \pm standard deviation (SD) of subjects in this study was $36 \pm 24.3$ where the early stage was 21.6 \pm 14.9 with 36 subject $(n=65)$ were in age $40-58$ year old and the late stage was $14.3 \pm 9.4$ with 25 subject $(n=43)$ were in age 40-59 year old. Results of linear regression test showed that there is a significant statistical relationship between early stage and high education level $(\mathrm{P}<0.001)$ better job $(\mathrm{P}<0.001)$ and high income $(\mathrm{P}<0.002)$.

Conclusion* There is significant relationship between socioeconomic status and prevalence of cervical cancer. A better job can leads to a better income and also high education level so that woman can access the healthcare facility to prevent the disease with consistent screening or to treat the cancer on the very early stage.

\section{INDOCYANINE GREEN TO ASSESS VASCULARITY OF ILEAL CONDUIT ANASTOMOSIS DURING PELVIC EXENTERATION FOR RECURRENT/PERSISTENT GYNECOLOGICAL CANCER}

${ }^{1} \mathrm{~N}$ Bizzarrit, ${ }^{2} \mathrm{~N}$ Foschi, ${ }^{1} \mathrm{M}$ Loverro, ${ }^{1} \mathrm{~L}$ Tortorella, ${ }^{3} \mathrm{~F}$ Santullo, ${ }^{1} \mathrm{~A}$ Rosati, ${ }^{1} \mathrm{~S}$ Gueli Alletti, ${ }^{1} \mathrm{~B}$ Costantini, ' $\mathrm{V}$ Gallotta, ${ }^{1} \mathrm{MG}$ Ferrandina, ${ }^{1} \mathrm{~A}$ Fagotti, ${ }^{1} \mathrm{~F}$ Fanfani, ${ }^{1} \mathrm{G}$ Scambia, ${ }^{1,4} \mathrm{G}$ Vizzielli. ${ }^{1}$ Fondazione Policlinico Universitario A. Gemelli, IRCCS, UOC Ginecologia Oncologica, Dipartimento per la salute della Donna e del Bambino e della Salute Pubblica, Rome, Italy; ${ }^{2}$ Fondazione Policlinico Universitario A. Gemelli, IRCCS, , UOC Clinica Urologica, Rome, Italy; ${ }^{3}$ Fondazione Policlinico Universitario A. Gemelli, IRCCS, UOC Chirurgia Peritoneo e Retroperitoneo, Dipartimento Scienze mediche e chirurgiche "Italy; ${ }^{4}$ University of Udine, Obstetrics and Gynecology Department, Udine, Italy

\subsection{6/ijgc-2021-ESG0.24}

Indocyanine green to assess vascularity of ileal conduit anastomosis during pelvic exenteration for recurrent/persistent gynecological cancer: a pilot study.

Introduction/Background* Pelvic exenteration performed for recurrent/persistent gynecological malignancies has been associated to urological short- and long-term morbidity, due to altered vascularization of tissues for previous radiotherapy. The aims of the present study were to describe the use of intravenous indocyanine green (ICG) to assess vascularity of urinary diversion (UD) after pelvic exenteration for gynecologic cancers, to evaluate the feasibility and safety of this technique and to assess the post-operative complications.

Methodology Prospective, observational, single-center, pilot study including consecutive patients undergoing anterior or total pelvic exenteration due to persistent/recurrent gynecologic cancers between $08 / 2020$ and $03 / 2021$ at Fondazione Policlinico Gemelli IRCCS, Rome, Italy. All patients underwent intravenous injection of $3-6 \mathrm{ml}$ of ICG $(1.25 \mathrm{mg} / \mathrm{ml})$ once the

Abstract 284 Table 2 Results of linear regression

\begin{tabular}{|c|c|c|c|c|c|c|}
\hline \multirow[t]{2}{*}{ Independent Variable } & \multicolumn{3}{|l|}{ Early stage } & \multicolumn{3}{|l|}{ Late stage } \\
\hline & The Regression Coefficient & Confidence Level & P Value & The Regression Coefficient & Confidence Level & $P$ Value \\
\hline High Education level & 3.9 & $2.03-5.8$ & 0.001 & 0.4 & $-2.1-2.01$ & 0.97 \\
\hline Better job & 2.7 & $1.1-4.3$ & 0.001 & 3.1 & $-2.4-8.5$ & 0.3 \\
\hline High income & -5.2 & $-8.4-1.9$ & 0.002 & 2.7 & $-5.5-10.9$ & 0.5 \\
\hline
\end{tabular}


UD was completed. A near infra-red camera was used to evaluate ICG perfusion of anastomoses (ileum-ileum, right and left ureter with small bowel and colostomy or colo-rectal sides of anastomosis) few second after ICG injection.

Result(s)* Fifteen patients were included in the study. No patient reported adverse reactions to ICG injection. Only 3/15 patients $(20.0 \%)$ had an optimal ICG perfusion $(+++)$ in all anastomoses. The remaining $12(80.0 \%)$ patients had at least one ICG deficit; the most common ICG deficit was on the left ureter: $3(20.0 \%)$ versus $1(6.7 \%)$ patient had no ICG perfusion (-) on the left versus right ureter, respectively $(p=0.598) .8 / 15 \quad(53.3 \%)$ and $6 / 15(40.0 \%)$ patients experienced $\geq$ grade 330 -day early and late postoperative complications, respectively. Of these, two patients had early and one had late postoperative complications directly related to poor perfusion of anastomosis (UD leak, ileum-ileum leak and benign ureteric stricture): all these cases had a sub-optimal intraoperative ICG perfusion.

Conclusion* The use of ICG to intra-operatively assess the anastomoses perfusion at time of pelvic exenteration for gynecologic malignancy is a feasible and safe technique. The different vascularization of anastomotic stumps may be related to anatomical sites and to previous radiation treatment. This approach could be of support in selecting patients at higher risk of complications, who may need personalized follow up.

\section{DOSE-DENSE NACT FOLLOWED BY CCRT IN LOCALLY ADVANCED CERVICAL CANCER: FEASIBILITY AND SAFETY}

${ }^{1} \mathrm{G}$ Parpinel ${ }^{*},{ }^{2} \mathrm{M}$ Buffa, ${ }^{3} \mathrm{JDI}$ Muzio, ${ }^{4} \mathrm{~A}$ Peruzzo Cornetto, ${ }^{5} \mathrm{C}$ Palladino, ${ }^{2} \mathrm{ME}$ Laudani, ${ }^{2} \mathrm{M}$ Barboni, ${ }^{2} \mathrm{E}$ Peirano, ${ }^{2} \mathrm{M}$ Girimonte, ${ }^{4} \mathrm{E}$ Madon, ${ }^{2} \mathrm{P}$ Zola. ${ }^{1}$ University of Turin, Surgical Sciences, Turin, Italy; ${ }^{2}$ University of Turin, Surgical Sciences, Italy; ${ }^{3}$ Città della Salute e della Scienza di Torino, Oncology and Radiation Oncology, Italy; ${ }^{4}$ Città della Salute e della Scienza di Torino, Medical Physics, Italy; ${ }^{5}$ University of Turin, Oncology and Radiation Oncology, Italy

\subsection{6/ijgc-2021-ESG0.25}

Introduction/Background* First-line treatment for locally advanced cervical cancer (LACC) is concurrent platinum chemoradiation therapy (CCRT) followed by cervico-vaginal brachytherapy (BT). Neoadjuvant chemotherapy (NACT) followed by $\mathrm{CCRT}+\mathrm{BT}$ has been proposed as an alternative scheme, but its feasibility is still investigational. The aim of this study was to evaluate safety and efficacy of this treatment.

Methodology In our Institution 30 patients with LACC have been treated between 2016-19. They received 6 cycles of weekly NACT with Carboplatin AUC 2 and Paclitaxel 80mg/ $\mathrm{mq}$, followed by CCRT (pelvic EBRT (45Gy) weekly Cisplatin $40 \mathrm{mg} / \mathrm{mq}$ followed by cervico-vaginal BT-HDR (10Gy).

Primary endpoints were 3-year overall survival (OS) and progression-free survival (PFS) while secondary endpoints were safety and toxicity.

Result(s)* The most frequent histological type was squamous cell carcinoma (80\%) and G3-grading (66,7\%).

9/30 patients had FIGO III stage. Radiological complete response (CR) after NACT was 3,3\% while partial response (PR) was $86,6 \%$; only 1 patient had progressive disease (PD).

21 patients $(70 \%)$ received more than 4 cycles of concurrent Cisplatin during EBRT, while 8 received less than 4 cycles.
After a median follow-up of 36.7 months 3-year OS and PFS values were $71.8 \%$ and $65.2 \%$, respectively. Patients with higher values of haemoglobin pre-CCRT (i.e. $>10 \mathrm{~g} / \mathrm{dl}$ ) reported a superior 3 -year OS value (i.e. $70 \%, \mathrm{n}=25$ ) vs $50 \%$ for patients with $<10 \mathrm{~g} / \mathrm{dl}(\mathrm{n}=5)$.

Local and lymph-node recurrence occurred in 30\% and $23 \%$ of patients while distant-metastasis in $10 \%$ of patients.

Only 1 patient experienced G3 anaemia after NACT while 3 cases of G3 haematological toxicity after CCRT+BT-HDR were observed. One patient had G3 neurotoxicity after NACT and 3 patients experienced G3 nausea and diarrhoea after CCRT+BT-HDR.

Conclusion* In our study NACT followed by CCRT+BT resulted to be a feasible treatment. Our data are consistent with the published literature in term of feasibility and safety and the NACT could by synergic with CCRT in the treatment of LACC.

\section{THE CASE OF CERVICAL CANCER IB3 WITH MIELOTOXITY AFTER 2 CYCLE OF CHEMOTADIOTHERAPY TREATED WITH RADICAL HYSTERECTOMY AS THE LAST METHOD OF CHOICE}

E Milnerowicz-Nabzdyk*, J Tomiczek-Szwiec, K Nowak, M Kalus. PZOZ Opolskie Centrum Onkologii im. prof. Tadeusza Koszarowskiego, Opole, Poland

\subsection{6/ijgc-2021-ESG0.26}

Introduction/Background* Patients with stage IB3 cervical cancer are usually qualified for radiochemotherapy. However, sometimes ther is a high toxicity of this treatment, which lead us to look for non-standard soltions. Nevertheless, we know that a combination of radical surgery, radiotherapy and chemotherapy is also burdened with a high toxicity.

Methodology Radical hysterectomy type C Querleu-Morrow and pelvic and para-aortic lymphadenectomy was performed with laparoscopy - as a minimally invasive procedure.

Result(s)* The case of a 27 year old lady with cervical cancer FIGO IB3 is qualified for chemoradiotherapy (Histopathology: Cervical adenocarcinoma G2). She had received $28 \mathrm{f}$ Grey and one cycle of cisplatin $(70 \mathrm{mg})$. The treatment was postponed because of huge myelotoxicity. As no other choice, she was qualified for radical hysterectomy type C Querleu-Morrow and pelvic - para-aortic lymphadenectomy. Radical hysterectomy was performed with laparoscopy - as a minimally invasive procedure that is less traumating for depressing immune system. Postoperative histopathology: cervix -chronic inflammation. There were observed no neoplastic changes in the uterus, fallopian tubes, ovaries, pelvic and para-aortic lymph nodes. One month after surgery there was observed massive vaginal fistula, massive inflamatory changes were visible in cystoscopy. Two months after surgery -bilateral hydronephrosis, both in double $\mathrm{J}$ ureteral stent were inserted. 5 months after surgery no hydronephrosis was detected, both double J stents from the ureters were removed. Next there were observed episodes of high urosepsis with bilateral hydronephrosis, finally 7 months after surgery - double J stends to both ureters were necessary.

Conclusion* We are conscious that finally, retransplantation of the ureters is necessary otherwise the patient will be obliged to continuous exchange of the double J stands in both ureters and the episodes of the urosepsis would reply - but if the urologic surgery is needed it could be done not earlier than 